\title{
A Flexible Load Control Strategy for Distribution Network to Reduce the Line Losses and to Eliminate the Transmission Congestion
}

\author{
Beibei Wang, ${ }^{1}$ Xiaoqing Hu, ${ }^{2}$ Peifeng Shen, ${ }^{3}$ Wenlu Ji, ${ }^{3}$ Yang Cao, ${ }^{4}$ and Jiaping Tang ${ }^{5}$ \\ ${ }^{1}$ School of Electrical Engineering, Southeast University, Nanjing 210096, China \\ ${ }^{2}$ State Grid Jiangsu Wuxi Power Supply Company, No. 12 Liangxi Street, Wuxi 214000, China \\ ${ }^{3}$ State Grid Jiangsu Nanjing Power Supply Company, No. 1 Aoti Street, Nanjing 210019, China \\ ${ }^{4}$ China Electric Power Research Institute, Nanjing 210003, China \\ ${ }^{5}$ State Grid Shanghai Maintenance Company, No. 600 Wuning Road, Shanghai 200063, China
}

Correspondence should be addressed to Xiaoqing Hu; happysnow2004@126.com

Received 16 March 2017; Accepted 13 June 2017; Published 20 July 2017

Academic Editor: Mauro Gaggero

Copyright (C) 2017 Beibei Wang et al. This is an open access article distributed under the Creative Commons Attribution License, which permits unrestricted use, distribution, and reproduction in any medium, provided the original work is properly cited.

\begin{abstract}
There are many uncertain factors in the modern distribution network, including the access of renewable energy sources and the heavy load level. The existence of these factors has brought challenges to the stability of the power distribution network, as well as increasing the risk of exceeding transmission capacity of distribution lines. The appearance of flexible load control technology provides a new idea to solve the above problems. Air conditioners (ACs) account for a great proportion of all loads. In this paper, the model of dispatching AC loads in the regional power grid is constructed, and the direct load control (DLC) method is adopted to reduce the load of ACs. An improved tabu search technique is proposed to solve the problem of network dispatch in distribution systems in order to reduce the resistive line losses and to eliminate the transmission congestion in lines under normal operating conditions. The optimal node solution is obtained to find the best location and reduction capacity of ACs for load control. To demonstrate the validity and effectiveness of the proposed method, a test system is studied. The numerical results are also given in this article, which reveal that the proposed method is promising.
\end{abstract}

\section{Introduction}

Distribution network is a bridge that connects transmission network and users. Its safety and reliability is the key factor that affects the reliability of power supply. Nowadays, the scale of modern distribution network is getting bigger and bigger; meanwhile, its connection becomes more and more complicated [1]. There are many uncertain factors in the modern distribution network, including the access of renewable energy sources and the heavy load level. The existence of these factors has brought challenges to the stability of the power distribution network, as well as increasing the risk of exceeding transmission capacity of distribution lines. The traditional control and management methods of distribution network are passive such as reconfiguration [2], adjusting OLTC (On-Load Tap-Changer) tap [3], switching reactive power compensation equipment [4], and load shedding [5]. There are a series of problems, such as low level of automation and backward scheduling method. In recent years, domestic and foreign scholars have also carried out the research of smart scheduling in power system. However, most of the research works focus on the transmission network [6], such as security and stability analysis and risk prevention, whereas the smart scheduling and flexible control in distribution network is usually ignored rather than carefully designed.

In the distribution network system, the load on each feeder is composed of industrial, commercial, and residential type loads [7]. Their load curves are different, which make the peak loads of feeders appear at different times. Therefore, under normal operating conditions, in order to reduce the power loss and improve the bus voltage, a part of the load can be transferred from heavily loaded lines to lightly loaded 
lines through network reconfiguration. During this process, the transformer capacity, the heat capacity of the feeder, the voltage drop, the line topology, and other constraints need to be satisfied. Civanlar et al. conducted the early research on feeder reconfiguration for loss reduction [8]. In [9], Baran and $\mathrm{Wu}$ modeled the problem of loss reduction and load balancing as an integer programming problem. In [10], the authors used a genetic algorithm to look for the minimum loss configuration. In [11, 12], the authors presented the use of the power flow method based on a heuristic algorithm to determine the minimum loss configuration to radial distribution networks. In [13], the authors proposed a solution procedure which employed simulated annealing to search for an acceptable noninferior solution.

However, during the summer peak periods, loads of feeders in the distribution network are too heavy to be transferred through network reconfiguration. In such an overload case, load shedding must be carried out $[5,14,15]$. Otherwise, there will be a risk of low voltage or even voltage collapse [16]. The traditional control and management mode of power distribution network are passive [17]. Its scheduling method is outdated and automation level is low [18]. There are two main ways to solve the problem of heavy load in the distribution network. One way is to find solutions from the power supply side. Wind power [19, 20], photovoltaic [21], and other renewable energy sources are connected to the distribution network according to the load situation [19]. Through active distribution network (ADN) [22], coordinated control technology is used to realize the effective management of bidirectional power flow [23] after distributed energy interfaced with the distribution network. This allows distributed energy to play a supporting role in the distribution network under reasonable regulatory and access standards [24]. Another way is to find solutions from the load side; technologies such as demand response (DR) and energy efficiency management (EEM) for load resources need to be energetically developed [25]. Using active response of flexible load to reduce peak load of distribution network at the time of overload can solve the problem of small adjustment margin of distribution network operation in the peak period [26], delay the reconstruction of the line and the new construction process, and save the investment of the power grid [27].

Thanks to the advancement of the communication capability of the new intelligent service network and the loads' controllability, there has been growing attention in methods inspired by the demand response technology in [28] to help achieve peak load shifting in the last decades. Electricity shortages usually occur during peak hours in summer or winter, when the percentage of the air conditioning loads reach $30 \% \sim 40 \%$ of the total capacity-the demand peak rises with the number of air conditioners (ACs) in use. Direct load control (DLC), which usually reduces the loads by controlling the thermostatically controlled loads (TCLs) of ACs [29], fridges, and water heaters of the residential users, is an important type of incentive-based demand response [30] to solve shortages in electricity supply and problems of energy spending during the summer season.

Recently, the study of DLC is as follows: Lee and Wilkins [31] proposed a general modeling technique for evaluating the effectiveness of load control. Bhatnager and Rahman [32] pointed out that the effect of the DLC control strategy depends on the system characteristics. Hsu and Su [33] proposed a dynamic programming approach to coordinate the DLC strategy and the generator output, so as to minimize the production cost of the system. Wei and Chen [34] presented a multichannel dynamic programming for DLC, which can quickly converge to a near optimal solution. In order to improve the customer's willingness to participate in DLC, the demand response control strategy based on fuzzy logic is used to control the air conditioning and water heater periodically. These kinds of loads are called flexible loads. They have a heat energy storage ability and can switch or change the control parameters in a short time, which will not impact users. Thus, the minimization of peak load by DLC methods has been suggested $[35,36]$. The aim of this paper is to find the optimal location and capacity of the AC loads to be reduced. As for the specific method and detailed process of AC loads control, they have been introduced in [37].

The main work and interesting findings in this paper are concluded as follows:

(i) Based on the actual connection and load characteristic of distribution network, the scheduling scheme of distribution network and the way of load control are studied.

(ii) Against the shortcomings of traditional calculation methods for distribution grid losses, an improved alternative method called the back/forward sweep algorithm is presented for power flow calculation.

(iii) Direct load control of regional distribution network can be realized by dispatching the regional AC loads. A new efficient and robust method based on tabu search technique is proposed to solve the problem of network dispatch in distribution systems in order to reduce the resistive line losses and to eliminate the transmission congestion in lines under normal operating conditions.

The rest of this paper is organized as follows. Section 2 presents a power flow calculation method based on the back/forward sweep algorithm. Section 3 formulates the problem of smart dispatching AC loads in the distribution network. Section 4 presents flexible load control based on the proposed algorithm. Section 5 provides case studies. Section 6 summarizes the discussions and puts forth our conclusions.

\section{Power Flow Calculation Based on the Back/Forward Sweep Algorithm}

2.1. Characteristics of Distribution Network. Compared with transmission network, distribution network has its own characteristics:

(1) The voltage level of distribution network is lower than that of the transmission network. The structure of distribution network, which is designed in closed loop and operated in open loop, is generally radial. 
(2) Back sweep: calculate node voltage

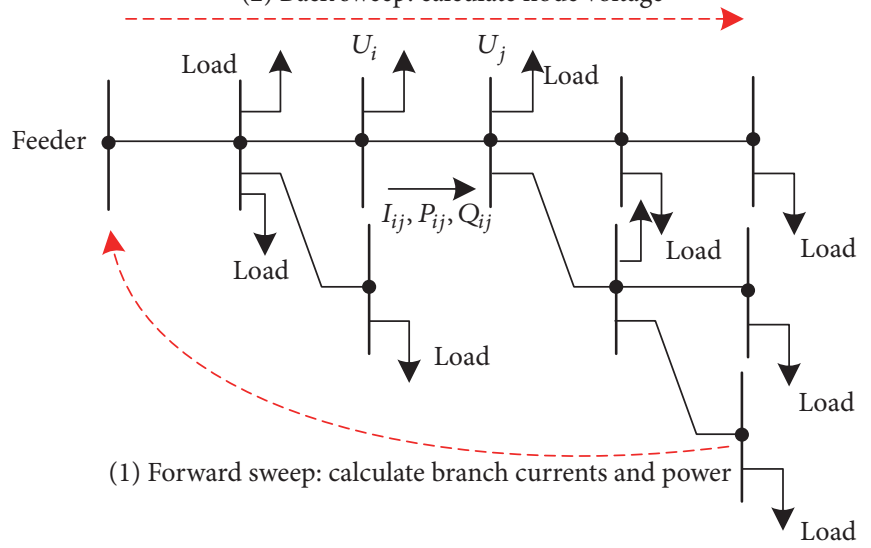

FIGURE 1: The schematic diagram of the back/forward sweep algorithm in distribution network.

(2) Compared with the transmission network, the diameter of the distribution network is small, the length is longer, and there are more branches, which result in a larger $\mathrm{R} / \mathrm{X}$ ratio of the distribution network line.

(3) The balance node in distribution network is at the end of the feeder, and there are many PQ nodes and few PV nodes in the power grid.

(4) In the low voltage distribution network, there are more single phase loads. There is a great difference of the user's way of consumption and the power supply capacity, which causes three-phase unbalance of distribution network.

The above differences lead to the dissatisfied convergence when calculating power flow of the distribution network by using the traditional method, such as Gauss Seidel method, P-Q decoupled method, and Newton-Raphson method. Because the improved tabu search algorithm used in this paper needs to repeatedly call the power flow calculation when scheduling the urban air conditioning loads, the efficiency of searching the best location and capacity of the AC loads to be cut is largely determined by the speed of power flow calculation. Against the shortcomings of traditional calculation methods for distribution grid losses, an improved alternative method is presented. This method takes into account influences on reactive power and voltage drop along distribution lines.

2.2. The Back/Forward Sweep Algorithm. Considering the characteristic of distribution networks, the back/forward sweep algorithm is used for power flow calculation. The algorithm starts from the end node. Forward sweep is to calculate branch currents and power. The power and current of each node are calculated against the direction of power flow by using the known load power of the end node. Back sweep is to calculate node voltage. Starting from the power supply node, the voltage of each bus is solved in the direction of power flow. These two processes are repeatedly performed until the voltage difference between the two consecutive iterations converges to a given accuracy. The main advantage of the algorithm is to adapt to the radial and open loop characteristics of distribution network. The schematic diagram of the whole process is shown in Figure 1. Detailed steps are as follows and the flowchart of the back/forward sweep algorithm is shown in Figure 2.

Step 1. First of all, it is assumed that the voltages of buses are equal to the rated voltage, and their phases are zero; that is, $U_{i}=1 \angle 0^{\circ}$, where $i$ is the corresponding node number.

Step 2. The injection current of each load node is calculated according to the injected power and the assumed voltage value of each node.

$$
I_{\text {in }}(j)=\operatorname{conj}\left(\frac{S_{j}}{U_{i}}\right) .
$$

Step 3 (forward calculation of the branch current). The node load current is added directly to the upstream branch current from the end of the feeder to the first node. The nodes are divided into three categories: the end node, the intermediate node, and the T node. Then, what type each node belongs to is determined, and the current of each branch can be calculated.

If the tail node $j$ of the branch $i j$ is the terminal node, the branch current is equal to the current of the load node

$$
I_{i j}=I_{\text {in }}(j) \text {. }
$$

If the tail node $j$ of the branch $i j$ is an intermediate node, the current of the load node plus the branch current of the next branch is equal to the branch current.

$$
I_{i j}=I_{\text {in }}(j)+I_{j, j+1} \text {. }
$$

If the tail node $j$ of the branch $i j$ is a T node, the current of the load node plus the branch current of all the subbranches plus the branch current of the next branch is equal to the branch current.

$$
I_{i j}=I_{\text {in }}(j)+I_{j, j+1}+\sum_{j_{1} \in j} I_{j, j_{1}}
$$

where $j_{1} \in j$ indicates that node $j_{1}$ is a child node which is connected to node $j$. 


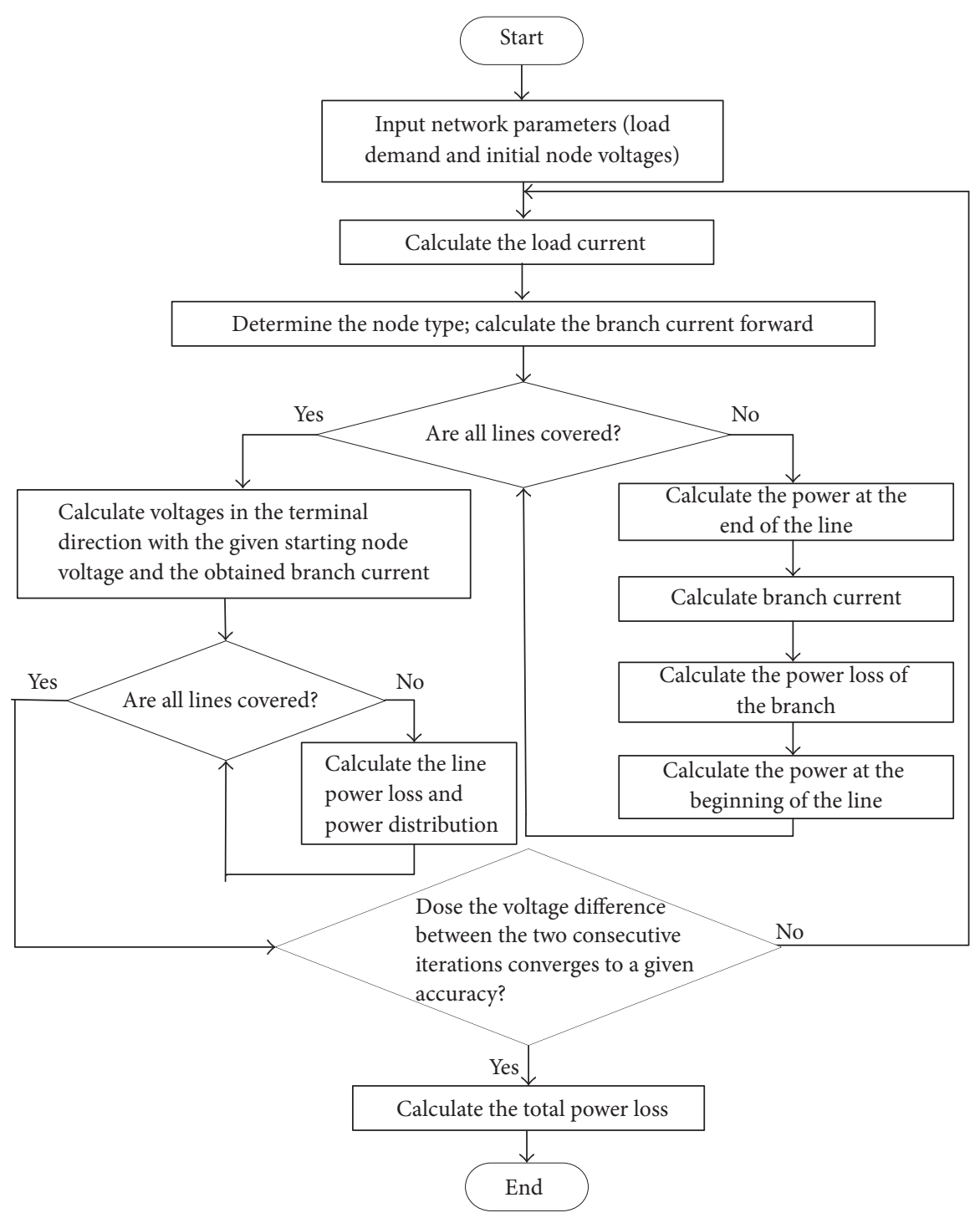

FIGURE 2: The flowchart of the back/forward sweep algorithm.

Step 4. On the premise that $i, j$ are, respectively, the head and terminal node of branch $k$, the apparent power at the beginning of the branch $i j$ is

$$
S_{i j}=S_{L j}+\sum_{k \in C_{j}} S_{j k}+\Delta S_{i j}=P_{i j}+j Q_{i j}
$$

whose parameters are

$$
\begin{aligned}
P_{i j}= & P_{L j}+\sum_{k \in C_{j}} P_{j k}+\Delta P_{i j} \\
= & P_{L j}+\sum_{k \in C_{j}} P_{j k} \\
& +\frac{\left(P_{j}+\sum_{k \in C_{j}} P_{j k}\right)^{2}+\left(Q_{j}+\sum_{k \in C_{j}} Q_{j k}\right)^{2}}{U_{j}^{2}} R_{i j}
\end{aligned}
$$

$$
\begin{aligned}
Q_{i j}= & Q_{L j}+\sum_{k \in C_{j}} Q_{j k}+\Delta Q_{i j} \\
= & Q_{L j}+\sum_{k \in C_{j}} Q_{j k} \\
& +\frac{\left(P_{j}+\sum_{k \in C_{j}} P_{j k}\right)^{2}+\left(Q_{j}+\sum_{k \in C_{j}} Q_{j k}\right)^{2}}{U_{j}^{2}} X_{i j},
\end{aligned}
$$

where $S_{i j}$ is the apparent power at the head of line $i j . S_{L j}$ represents the load power demand of node $j . \Delta S_{i j}$ is for power consumption in line $i j . C_{j}$ is a set of nodes which are all connected to node $j$ except node $i$. The sum of the active power of all the branches connected to node $j$ except line $i j$ is $\sum_{k \in C_{j}} P_{j k}$. Similarly, the sum of the reactive power of all the branches connected to node $j$ except line $i j$ is $\sum_{k \in C_{j}} Q_{j k}$. 
The apparent power loss of the line $i j$ is

$$
\Delta S_{i j}=I_{i j}^{2}\left(R_{i j}+j X_{i j}\right) .
$$

Step 5. In the process of back sweep, the voltage drop towards the end of the feeder can be worked out by using the given head voltage and the obtained head power. Thus the voltage of each bus is got without calculating the power flow.

$$
\begin{aligned}
& U_{j}=\sqrt{\left(U_{i}-\frac{P_{i j} R_{i j}+Q_{i j} X_{i j}}{U_{i}}\right)^{2}+\left(\frac{P_{i j} X_{i j}-Q_{i j} R_{i j}}{U_{i}}\right)^{2}} \\
& \theta_{j}=\theta_{i}-\arctan \frac{\left(P_{i j} X_{i j}-Q_{i j} R_{i j}\right) / U_{i}}{U_{i}-\left(P_{i j} R_{i j}+Q_{i j} X_{i j}\right) / U_{i}} .
\end{aligned}
$$

Step 6. Whether the voltage difference between the two consecutive iterations converges to a given accuracy, that is, $\varepsilon=10^{-9} \mathrm{kV}$, can be determined according to the formula

$$
\left|U_{i}^{(k+1)}-U_{i}^{(k)}\right| \leq \varepsilon,
$$

where $U_{i}^{(k)}$ represents the voltage of node $i$ at the $k$ th iteration.

Step 7. If the convergence criterion is not satisfied, for the next iteration, the average voltage of each node, which is used as the initial voltage, is replaced by the obtained voltage in the last iteration. Then, repeat the above process until the convergence condition is satisfied.

\section{Problem Formulation of Smart Dispatching AC Loads in the Distribution Network}

The objective of the model describing the studied problem is to minimize the system power loss and node voltage offset and also to eliminate the transmission congestion. This model can be expressed as follows:

$$
\begin{aligned}
\operatorname{Max} f= & \lambda_{1} \cdot\left(P_{\text {sum } 0}-P_{\text {sum }}\right)-\lambda_{2} \\
& \cdot\left(1-\frac{\min \left(V_{i \in N}\right)}{V_{L}} \cdot 100 \%\right)
\end{aligned}
$$

whose parameters are

$$
P_{\text {sum }}=\sum_{i=1}^{N} R_{i} \frac{\left(P_{i}^{2}+Q_{i}^{2}\right)}{U_{i}^{2}} .
$$

In order to achieve this goal, an improved tabu search algorithm is used to find the best location and reduction capacity of ACs for load control. The first item in (10) is the difference of the total loss of the distribution network before and after the occurrence of the demand response, and the second one is the voltage offset of each node, in which $N$ is the total number of nodes in distribution network. $P_{i}$ and $Q_{i}$, respectively, represent the active power and reactive power injected into node $i . U_{i}$ and $R_{i}$ are the terminal node voltage and resistance of branch $b_{i} . P_{\text {sum }}$ is the system power loss after load control, whereas $P_{\text {sum } 0}$ is the initial system power loss before load control. $V_{i \in N}$ represents that $N$ is the set of nodes. $V_{L}$ is the rated voltage. $\lambda_{1}, \lambda_{2}$ are the weight coefficients of the multiobjective optimization.

It is subject to the following:

(1) Conservation of power flow:

$$
\begin{aligned}
P_{i} & =V_{i} \sum_{j=1}^{N} V_{j}\left(G_{i j} \cos \theta_{i j}+B_{i j} \sin \theta_{i j}\right) \\
Q_{i} & =V_{i} \sum_{j=1}^{N} V_{j}\left(G_{i j} \sin \theta_{i j}-\cos B_{i j} \theta_{i j}\right),
\end{aligned}
$$

where $V_{i}$ is the voltage of node $i$ and $G_{i j}, B_{i j}$, and $\theta_{i j}$ are the conductance, susceptance, and phase angle of branch $i j$.

(2) Node voltage limits:

$$
U_{\min } \leq U_{i} \leq U_{\max }
$$

where $U_{\min }$ and $U_{\max }$, respectively, represent the upper and lower limits of the voltage at bus $i$.

(3) Branch current limits:

$$
I_{i}<I_{i, \max }, \quad i=1,2, \ldots, n,
$$

where $I_{i}$ is the current flowing through branch $b_{i}$, and $I_{i, \max }$ is the maximum value allowed.

(4) Transmission capacity limits of distribution line:

$$
P^{2}+Q^{2} \leq S_{i \max }^{2}
$$

where $P, Q$ are the active power and reactive power of branch i. $S_{i \max }$ is the upper limit on the transmission capacity of the distribution line.

(5) Capacity limits of the flexible load reduction:

$$
0 \leq \max S_{\mathrm{DR}}<0.4 * S_{k}^{\max } .
$$

We assume that the maximum flexible load accounts for $40 \%$ of the peak load at each end node. The amount of AC loads to be cut at each node should not exceed this capacity.

(6) Power factor of the $10 \mathrm{kV}$ side of the power supply being in line with the requirements:

$$
\sum_{i=1}^{n} Q_{i}=P_{i}\left[\tan \left(\arccos \varphi_{1}\right)-\tan \left(\arccos \varphi_{2}\right)\right] .
$$

The effect of flexible load scheduling in distribution network can be evaluated by three criteria. First of all, based on the proposed improved tabu search technique, the transmission congestion in lines can be eliminated. Furthermore, the resistive line losses can be reduced. Last but not least, the voltage offset level drops. 


\section{Flexible Load Control of Distribution Network Based on the Improved Tabu Search Algorithm}

Tabu search uses a flexible storage structure and the corresponding tabu criterion to avoid repeated detour searches. The core of the algorithm is to mark the local optimal solution which has been searched. Then, try to avoid these objects through the taboo rule, and search in other areas of the solution space in the next iterative search process to ensure the diversity of the search path. The local optimal solution in the neighborhood can be found. Also, according to aspiration criteria, TS can assoil some good solution status which has been tabued to get the globe optimum value. The main computational processes of the improved tabu search algorithm for scheduling ACs are stated below.

Step 1. Enter the raw data, like the distribution network parameters, taboo step size, and so on. In this paper, the solution vector is composed of the location and the load capacity to be reduced of $n$ central ACs. That is, $x=$ $\left[n_{f 1}, \ldots, n_{f n} ; S_{\mathrm{DR} f 1}, \ldots, S_{\mathrm{DR} f m}\right]$, where $n_{f 1}, \ldots, n_{f n}$ are the node numbers and $S_{\mathrm{DR} f 1}, \ldots, S_{\mathrm{DR} f m}$ are the load reduction capacity.

Step 2. Calculate the initial total loss $P_{\text {sum } 0}$ of the distribution network and the transmission power of each line by calling the power flow calculation program.

Step 3. Two nodes are randomly selected as the initial node to carry out load reduction. In a certain range, the AC loads at the selected nodes are reduced by random values. The system power loss can be calculated by the power flow program and is used as an initial test solution for the tabu search.

Step 4. End the process if "After 10 successive iterations, the fitness is always kept constant" or "The maximum iteration number is reached" is satisfied; otherwise, repeat the outer loop. Search in the neighborhood of the initial solution to generate the test solution, and then call the power flow calculation to get the fitness value, which is the variation of the total loss of the distribution network. And then the local optimal solution in the neighborhood is generated in order. The neighborhood search in the distribution network is divided into two parts: neighborhood search for the load node location and for the reduced capacity.

(1) Neighborhood Search for the Position of the Load Reduction Node. (a) First, the type of the first node $n_{f 1}$ in the initial solution vector is determined. If it belongs to a common node, its neighboring upstream and downstream nodes are taken as the first set of the load positions to be reduced, and their fitness values are calculated, respectively; (b) in the next $i$ th search, if the upstream node of node $n_{i}$ is a $T$ type node, all nodes in the upper reaches of $n_{i}$ should have a load cut, and their fitness values are calculated; (c) if $n_{i}$ itself is a $T$ type node, then all nodes in the lower reaches of $n_{i}$ need to carry out a load reduction; also their fitness values are calculated.
(2) Neighborhood Search for the Capacity of the Load Reduction. The traditional neighborhood search is to select several nominal capacities as the neighborhood and then to calculate the fitness. In order to avoid the limitations of the traditional neighborhood search for capacity reduction, in this paper, a fixed, tiny step size $d$ is used as the neighborhood of the load reduction capacity. By doing so, it will help to expand the scope of the neighborhood search and to obtain the global optimum. The procedure of neighborhood search is as follows: (a) the optional range of active capacity for each node load to be reduced is $P \in\left[0, d, 2 d, \ldots, P_{\text {cutMax }}\right]$, among which $P_{\text {cutMax }}$ is the maximum value of air conditioning loads that a node can reduce; (b) if $\beta \mathrm{MW}$, which is the load reduction capacity, is neither the first element nor the last element in $P$, then two elements $\beta+d$ and $\beta-d$, which are in front of and behind $\beta$, are taken as neighborhood solutions; (c) if the value of the load reduction is the first element $0 \mathrm{MW}$ in the array $P$, only its next element is the neighborhood solution; (d) if the value of the load reduction is the last element $P_{\text {cutMax }}$ $\mathrm{MW}$ in the array $P$, only the last element is the neighborhood solution.

Step 5. Constraint conditions are checked for the test solutions in all neighborhoods. All the test solutions that satisfy the constraint conditions are sorted according to the value of the objective function. Then try to move a step from the best test solution and check whether the move is prohibited in the tabu list or whether it meets the aspiration criterion. If the motion is forbidden and does not satisfy the aspiration criterion, the suboptimal solutions are tried in order. The nontabu optimal candidate solution is taken as the best so far. The tabu list is updated, and then go to step 4. The taboo table records the number of steps, directions, or target values that have passed before, barred from returning, in order to prevent the search process cycle and fall into local optimum. The tabu list is dynamically updated; it records the latest solution and releases the oldest solution.

Step 6. The rule of contempt is adopted globally. The optimal solution to date has been recorded. The iteration process is repeated until the objective function has not changed within the specified 10 times. Then output the final result. Otherwise, go back to step 4 and proceed with the iteration.

Figure 3 shows the flowchart of the tabu search algorithm for flexible load scheduling in distribution network.

\section{Numerical Examples}

5.1. Simulation Conditions. The proposed approach for distribution network load reduction is tested on a 34-bus distribution system as shown in Figure 4. System data and parameters are listed in Tables 1 and 2. The transmission capacity of lines 4-5 is limited to 90 MVA. There are 34 nodes in this distribution line, of which 29 are load nodes and 4 are T-junctions. Besides, 1 power point and 5 peripheral nodes are also included. The initial voltage is $10.5 \mathrm{kV}$, the initial phase is 0 , and the capacity reference value is $100 \mathrm{MVA}$. Power distribution of load nodes is shown in Table 1, and the impedance of each feeder is shown in Table 2. Firstly, 


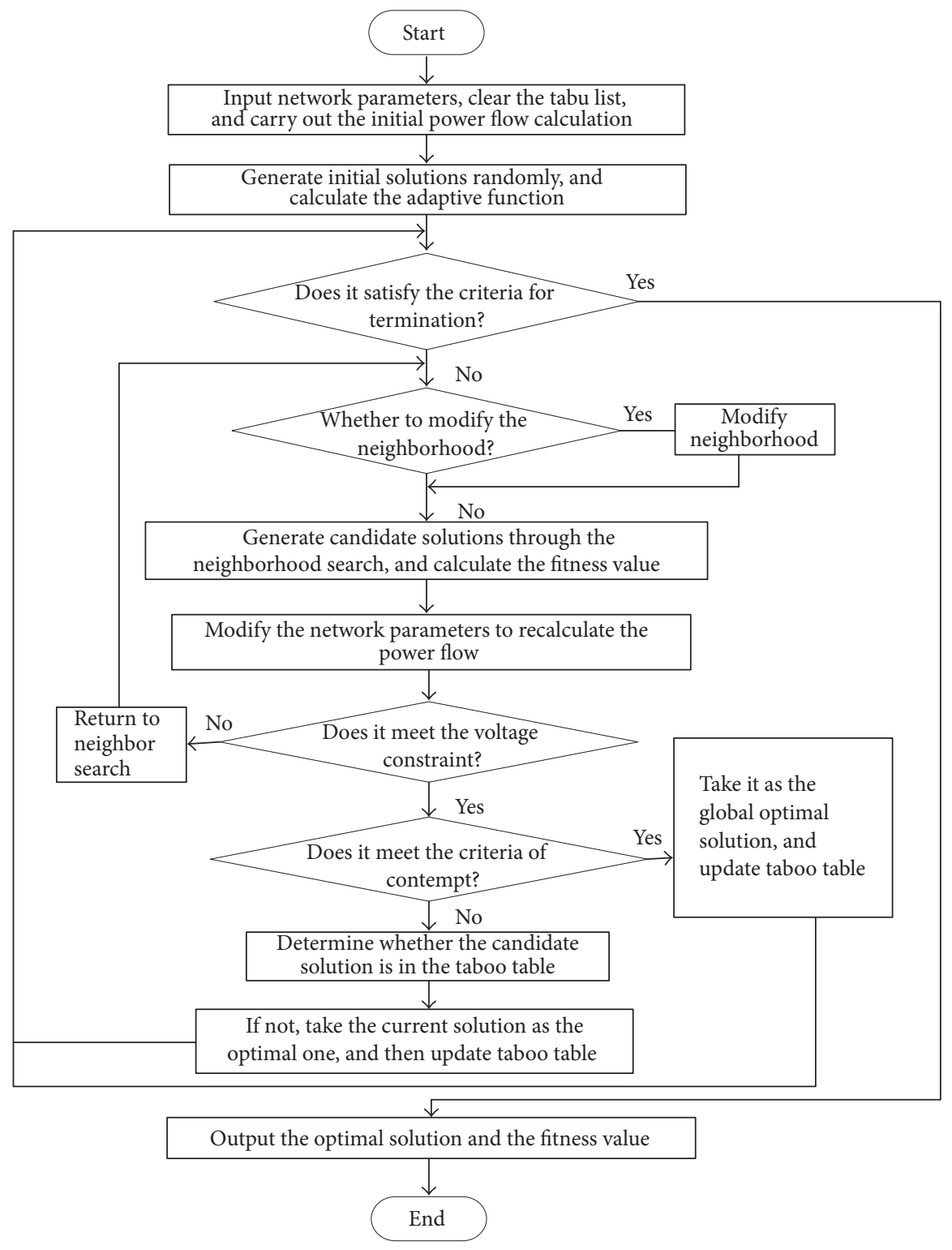

FIGURE 3: Flowchart of the tabu search algorithm for flexible load scheduling in distribution network.

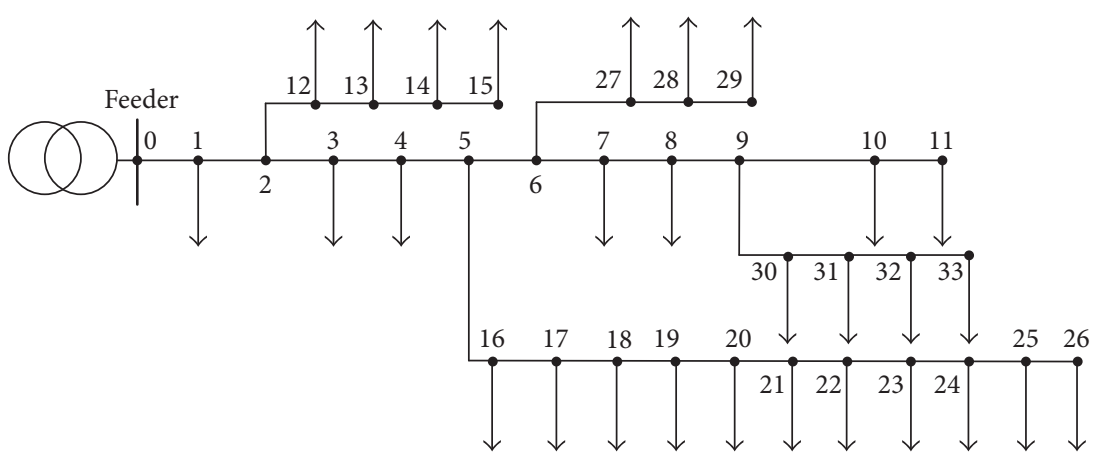

FIGURE 4: A 34-bus distribution system. 
TABLE 1: Power distribution of load nodes in a 34-bus distribution system.

\begin{tabular}{|c|c|c|}
\hline \multirow{2}{*}{ Node number } & \multicolumn{2}{|c|}{ Receiving node } \\
\hline & $P(\mathrm{MW})$ & $Q$ (MVar) \\
\hline 0 & 0 & 0 \\
\hline 1 & 4.6 & 2.85 \\
\hline 2 & 0 & 0 \\
\hline 3 & 4.6 & 2.85 \\
\hline 4 & 4.6 & 2.85 \\
\hline 5 & 0 & 0 \\
\hline 6 & 0 & 0 \\
\hline 7 & 4.6 & 2.85 \\
\hline 8 & 4.6 & 2.85 \\
\hline 9 & 0 & 0 \\
\hline 10 & 4.6 & 2.85 \\
\hline 11 & 2.74 & 1.68 \\
\hline 12 & 1.44 & 0.9 \\
\hline 13 & 1.44 & 0.9 \\
\hline 14 & 1.44 & 0.9 \\
\hline 15 & 0.27 & 0.15 \\
\hline 16 & 4.6 & 2.85 \\
\hline 17 & 4.6 & 2.85 \\
\hline 18 & 4.6 & 2.85 \\
\hline 19 & 4.6 & 2.85 \\
\hline 20 & 4.6 & 2.85 \\
\hline 21 & 4.6 & 2.85 \\
\hline 22 & 4.6 & 2.85 \\
\hline 23 & 4.6 & 2.85 \\
\hline 24 & 4.6 & 2.85 \\
\hline 25 & 4.6 & 2.85 \\
\hline 26 & 2.74 & 1.7 \\
\hline 27 & 1.5 & 0.96 \\
\hline 28 & 1.5 & 0.96 \\
\hline 29 & 1.5 & 0.96 \\
\hline 30 & 1.14 & 0.69 \\
\hline 31 & 1.14 & 0.69 \\
\hline 32 & 1.14 & 0.69 \\
\hline 33 & 1.14 & 0.69 \\
\hline
\end{tabular}

the initial power flow calculation is carried out based on the proposed back/forward sweep algorithm. Then the flexible load participating in the demand response is dispatched through the improved tabu search algorithm to eliminate network congestion on lines $4-5$, while reducing the line loss rate and the voltage offset. The number of selected load reduction nodes is two.

The impedance of each feeder in the 34-bus distribution system of this paper comes from the actual data of the lines between the 34 buildings in the central business district of Nanjing. Compared with the IEEE 33-bus radial distribution system, the diameter of the 34-bus distribution network is smaller, the length is longer, and there are more branches, which result in a much larger $\mathrm{R} / \mathrm{X}$ ratio of the distribution network line.

5.2. Results of Initial Power Flow Calculation. Initial power flow calculations based on the back/forward sweep algorithm are performed on the 34-bus distribution system above. The terminal condition of the iteration is that the difference of the voltage of the head node between two iterations is no more than $\varepsilon=10^{-6}$. After four iterations, the convergence condition is satisfied. Table 3 shows the amplitude and phase angle of each bus voltage worked out by the proposed method. Table 4 shows the active and reactive power of each branch.

Simulation results show that the proposed power flow method has the characteristics of the small occupation of memory, fast speed, and reliable convergence. It can be applied to determine the location of the AC loads and their reduction capacity.

5.3. The Result of AC Loads Reduction Decision Based on the Proposed Algorithm. The total load of the 34-node distribution network system is $92.73 \mathrm{MW}$, and the reactive load is 57.47 MVar. After the initial power flow calculation, the total active power of the system is $97.1645 \mathrm{MW}$; the active loss is $4.4345 \mathrm{MW}$. Similarly, the total reactive power of the system is $58.7722 \mathrm{MVar}$, and the reactive power loss is $1.3022 \mathrm{MVar}$. The reference voltage was chosen to be $10.5 \mathrm{kV}$. The voltage amplitude at the end of the distribution network is $10.079 \mathrm{kV}$. The line loss rate of the system is about $4.4345 \%$. The transmission power on lines 4-5 is 90.4014 MVA. Assuming that the transmission power of the lines 4-5 is limited to $90 \mathrm{MVA}$, it is desirable to dispatch the central AC load located at each node by using an improved tabu search algorithm to eliminate network congestion on lines 4-5, while minimizing the line loss and voltage drift. The number of nodes selected to carry out load reduction is two.

The initial solution vector is chosen as $\psi=[7,11,0.36$, $0.58,0.27,0.435]$. That is to say, the central ACs at node 7 and node 11 are selected for load reduction and reduced the active power output by $0.36 \mathrm{MW}$ and $0.58 \mathrm{MW}$, respectively. Assuming that the power factor of the controlled AC load is 0.8 , then the corresponding reductions in reactive capacity are, respectively, 0.27 MVar and 0.435 MVar.

Details of neighborhood search for the location of the load reduction nodes are as follows. First, the node type of the first element of the solution vector $\psi$ is judged. Then, according to the proposed neighborhood search method, find the load position to be cut and calculate the corresponding fitness value. After the above steps, the subneighborhood solution vector $\mathbf{x}_{1}$ is obtained. The number of its columns is 4 , but the number of rows is determined by the topological relation of node 7 . In this case, the subregions $\mathbf{x}_{\mathbf{2}}$ to $\mathbf{x}_{\mathbf{4}}$ are invariant. The search process of subneighborhood $\mathbf{x}_{2}$ coincides with that of $\mathbf{x}_{1}$. Both $\mathbf{x}_{1}$ and $\mathbf{x}_{2}$ are representative of the position of ACs that need to reduce the load.

Details of neighborhood search for the capacity of the load reduction node are as follows. Assume that the capacity range for each node to reduce the load is $P \in[0,0.001$, $0.002, \ldots, 4.6]$ MW. The search step is set as $d=1 \times$ $10^{-3} \mathrm{MW}$. The corresponding reactive power reduction range 
TABLE 2: Impedance of each feeder.

\begin{tabular}{|c|c|c|c|c|}
\hline Node $i$ & Node $j$ & $\begin{array}{c}\text { Resistance per unit length } \\
(\Omega / \mathrm{km})\end{array}$ & $\begin{array}{c}\text { Reactance per unit length } \\
(\Omega / \mathrm{km})\end{array}$ & $\begin{array}{c}\text { Line length } \\
(\mathrm{km})\end{array}$ \\
\hline 0 & 1 & 0.195 & 0.080 & 0.60 \\
\hline 1 & 2 & 0.195 & 0.080 & 0.55 \\
\hline 2 & 3 & 0.299 & 0.083 & 0.55 \\
\hline 3 & 4 & 0.299 & 0.830 & 0.50 \\
\hline 4 & 5 & 0.299 & 0.830 & 0.5 \\
\hline 5 & 6 & 0.524 & 0.090 & 0.60 \\
\hline 6 & 7 & 0.524 & 0.090 & 0.40 \\
\hline 7 & 8 & 0.524 & 0.090 & 0.60 \\
\hline 8 & 9 & 0.524 & 0.090 & 0.40 \\
\hline 9 & 10 & 0.524 & 0.090 & 0.25 \\
\hline 10 & 11 & 0.524 & 0.090 & 0.20 \\
\hline 2 & 12 & 0.524 & 0.090 & 0.30 \\
\hline 12 & 13 & 0.524 & 0.090 & 0.40 \\
\hline 13 & 14 & 0.524 & 0.090 & 0.20 \\
\hline 14 & 15 & 0.524 & 0.090 & 0.10 \\
\hline 5 & 16 & 0.299 & 0.083 & 0.60 \\
\hline 16 & 17 & 0.299 & 0.083 & 0.55 \\
\hline 17 & 18 & 0.378 & 0.086 & 0.55 \\
\hline 18 & 19 & 0.378 & 0.086 & 0.50 \\
\hline 19 & 20 & 0.378 & 0.086 & 0.50 \\
\hline 20 & 21 & 0.524 & 0.090 & 0.50 \\
\hline 21 & 22 & 0.524 & 0.090 & 0.50 \\
\hline 22 & 23 & 0.524 & 0.090 & 0.60 \\
\hline 23 & 24 & 0.524 & 0.090 & 0.40 \\
\hline 24 & 25 & 0.524 & 0.090 & 0.25 \\
\hline 25 & 26 & 0.524 & 0.090 & 0.20 \\
\hline 6 & 27 & 0.524 & 0.090 & 0.30 \\
\hline 27 & 28 & 0.524 & 0.090 & 0.30 \\
\hline 28 & 29 & 0.524 & 0.090 & 0.30 \\
\hline 9 & 30 & 0.524 & 0.090 & 0.30 \\
\hline 30 & 31 & 0.524 & 0.090 & 0.40 \\
\hline 31 & 32 & 0.524 & 0.090 & 0.30 \\
\hline 32 & 33 & 0.524 & 0.090 & 0.20 \\
\hline
\end{tabular}

is $Q \in[0,2.85]$ MVar. At each node, the AC load does not exceed $40 \%$ of the total load. The node type of the third element $0.36 \mathrm{MW}$ of the solution vector $\psi=[7,11,0.36$, $0.58,0.27,0.435]$ is judged. Then, according to step 4 of the proposed neighborhood search method, find the load capacity to be cut and calculate the corresponding fitness value. Thus, the third subneighborhood element $\mathbf{x}_{\mathbf{3}}$ of the neighborhood solution set $\phi$ is obtained. At this time the other elements $\mathbf{x}_{\mathbf{1}}, \mathbf{x}_{\mathbf{2}}$, and $\mathbf{x}_{\mathbf{4}}$ remain unchanged. The search process of $\mathbf{x}_{\mathbf{4}}$ coincides with that of $\mathbf{x}_{\mathbf{3}}$. Finally, all subneighborhood solutions $\mathbf{x}_{1}, \mathbf{x}_{2}, \mathbf{x}_{3}$, and $\mathbf{x}_{\mathbf{4}}$ are combined as neighborhood solutions $\phi=\left[\mathbf{x}_{1} ; \mathbf{x}_{2} ; \mathbf{x}_{3} ; \mathbf{x}_{\mathbf{4}}\right]$.
The length of the tabu list is set to 4 , and the scope of the aspiration criterion is set to global. The improved tabu search algorithm repeatedly calls the power flow calculation and neighborhood search. After 345 iterations, the optimal scheme of AC loads reduction in the distribution network was calculated.

The iterative optimization process of the proposed improved tabu search algorithm is presented in Figure 5(a). It shows the relationship between the number of iterations and the objective function. It can be seen that as the number of iterations increases, the fitness of the objective function increases gradually from the initial 0.25 until it stabilizes at 
TABLE 3: The amplitude and phase angle of each bus voltage.

\begin{tabular}{|c|c|c|}
\hline Bus number & $\begin{array}{l}\text { Voltage amplitude } \\
\text { (p.u.) }\end{array}$ & $\begin{array}{c}\text { Voltage phase } \\
\left(^{\circ}\right)\end{array}$ \\
\hline 0 & 1 & 0 \\
\hline 1 & 0.9941 & 0.0527 \\
\hline 2 & 0.9890 & 0.0990 \\
\hline 3 & 0.9821 & 0.2133 \\
\hline 4 & 0.9761 & 0.3127 \\
\hline 5 & 0.9704 & 0.4075 \\
\hline 6 & 0.9666 & 0.4985 \\
\hline 7 & 0.9645 & 0.5484 \\
\hline 8 & 0.9620 & 0.6070 \\
\hline 9 & 0.9608 & 0.6351 \\
\hline 10 & 0.9604 & 0.6461 \\
\hline 11 & 0.9602 & 0.6494 \\
\hline 12 & 0.9887 & 0.1069 \\
\hline 13 & 0.9884 & 0.1140 \\
\hline 14 & 0.9883 & 0.1160 \\
\hline 15 & 0.9883 & 0.1161 \\
\hline 16 & 0.9660 & 0.4828 \\
\hline 17 & 0.9622 & 0.5458 \\
\hline 18 & 0.9581 & 0.6285 \\
\hline 19 & 0.9549 & 0.6954 \\
\hline 20 & 0.9520 & 0.7539 \\
\hline 21 & 0.9487 & 0.8331 \\
\hline 22 & 0.9460 & 0.8985 \\
\hline 23 & 0.9435 & 0.9603 \\
\hline 24 & 0.9423 & 0.9902 \\
\hline 25 & 0.9418 & 1.0017 \\
\hline 26 & 0.9417 & 1.0051 \\
\hline 27 & 0.9663 & 0.5069 \\
\hline 28 & 0.9660 & 0.5125 \\
\hline 29 & 0.9659 & 0.5153 \\
\hline 30 & 0.9605 & 0.6431 \\
\hline 31 & 0.9601 & 0.6511 \\
\hline 32 & 0.9600 & 0.6551 \\
\hline 33 & 0.9599 & 0.6564 \\
\hline
\end{tabular}

about 1.6, which represents the change of the total power loss of the system. The red circle in the figure shows that, between 50 and 100 iterations, there is a sudden increase in the fitness value. For, at the 69th iteration, the tabu list and aspiration criterion are used to prevent the neighborhood search from falling into the local optimum. This reflects the superiority of the proposed method of distribution network scheduling based on improved tabu search. Figures 5(b) and $5(\mathrm{c})$, respectively, illustrate the neighborhood search processes of the location and the capacity of peak load

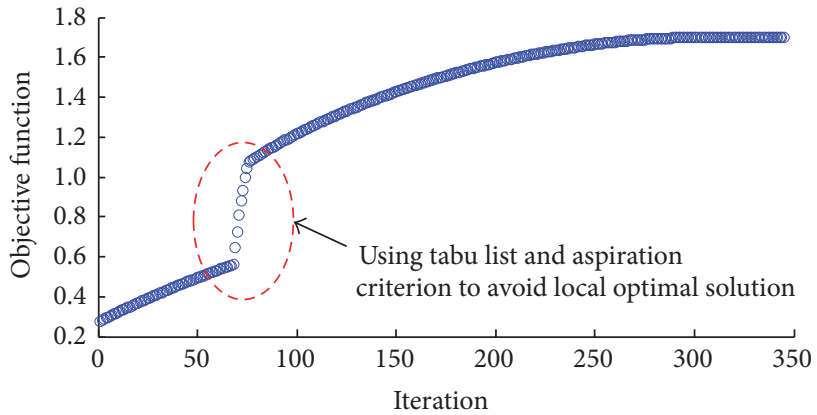

(a) Iterative optimization process of the proposed algorithm

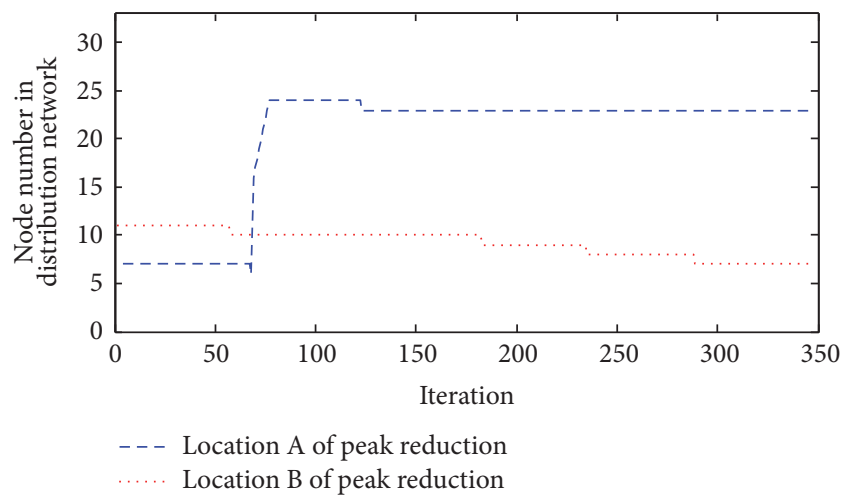

(b) Iterative search process of the location of ACs for peak reduction

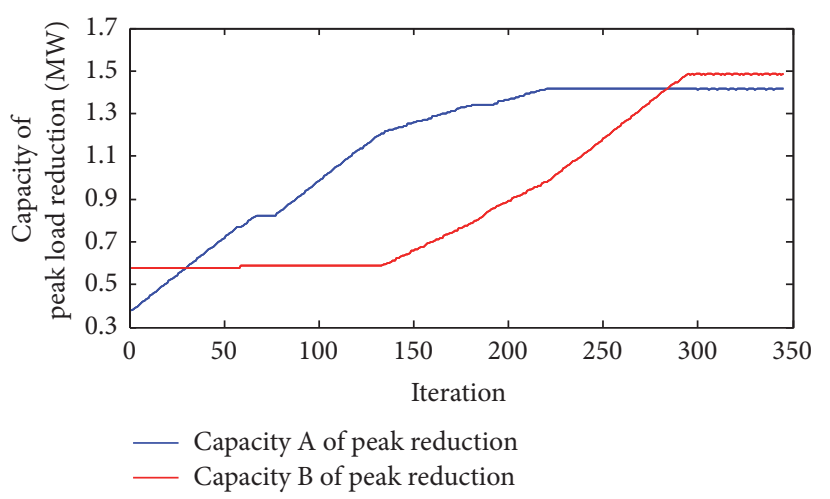

(c) Iterative search process of the capacity of ACs for peak reduction

FIGURE 5: Iterative optimization processes of flexible load reduction in distribution networks based on the proposed algorithm.

reduction. Finally, after 345 iterations, the optimal location and capacity for load reduction were found, and the target with the lowest power loss and the smallest node voltage offset is achieved.

Table 5 shows search results for position and capacity of load reduction in a 34-bus system based on the proposed algorithm. After the improved tabu search algorithm for optimal scheduling, the power output was reduced by $1.448 \mathrm{MW}$ and $1.52 \mathrm{MW}$, respectively, at node 23 and node 7 to eliminate the transmission congestion in lines $4-5$ while minimizing the system power loss.

Based on the discussions above, taking reducing the power of ACs by $1.52 \mathrm{MW}$ at node 7 as an example, we 
TABLE 4: The active and reactive power of each branch.

\begin{tabular}{|c|c|c|c|c|c|c|c|}
\hline \multirow{2}{*}{ Line number } & \multirow{2}{*}{ Node $i$} & \multirow{2}{*}{ Node $j$} & \multicolumn{2}{|c|}{ Start node } & \multicolumn{2}{|c|}{ End node } & \multirow{2}{*}{$\begin{array}{l}\text { Power loss of each line } \\
(\mathrm{kVA})\end{array}$} \\
\hline & & & $P(\mathrm{MW})$ & $Q$ (MVar) & $P(\mathrm{MW})$ & $Q($ MVar) & \\
\hline 1 & 0 & 1 & 97.1645 & 58.7722 & 96.5410 & 58.5164 & $623.442+255.77 j$ \\
\hline 2 & 1 & 2 & 91.9410 & 55.6664 & 91.4230 & 55.4539 & $518.016+212.52 j$ \\
\hline 3 & 2 & 3 & 86.8297 & 52.6033 & 86.1137 & 52.4046 & $716.01+198.758 j$ \\
\hline 4 & 3 & 4 & 81.5137 & 49.5546 & 80.9308 & 49.3928 & $582.912+161.812 j$ \\
\hline 5 & 4 & 5 & 76.3308 & 46.5428 & 75.8125 & 46.3989 & $518.274+143.868 j$ \\
\hline 6 & 5 & 6 & 25.8679 & 15.9160 & 25.7406 & 15.8942 & $127.264+21.858 j$ \\
\hline 7 & 6 & 7 & 21.2375 & 13.0136 & 21.1800 & 13.0037 & $57.512+9.878 j$ \\
\hline 8 & 7 & 8 & 16.5800 & 10.1537 & 16.5272 & 10.1447 & $52.792+9.068 j$ \\
\hline 9 & 8 & 9 & 11.9272 & 7.2947 & 11.9089 & 7.2915 & $18.294+3.142 j$ \\
\hline 10 & 9 & 10 & 7.3449 & 4.5308 & 7.3405 & 4.5301 & $4.366+0.75 j$ \\
\hline 11 & 10 & 11 & 2.7405 & 1.6801 & 2.7400 & 1.6800 & $0.486+0.084 j$ \\
\hline 12 & 2 & 12 & 4.5933 & 2.8506 & 4.5914 & 2.8502 & $1.94+0.334 j$ \\
\hline 13 & 12 & 13 & 3.1514 & 1.9502 & 3.1502 & 1.9500 & $1.216+0.21 j$ \\
\hline 14 & 13 & 14 & 1.7102 & 1.0500 & 1.7100 & 1.0500 & $0.178+0.03 j$ \\
\hline 15 & 14 & 15 & 0.2700 & 0.1500 & 0.2700 & 0.1500 & $0.002+0.012 j$ \\
\hline 16 & 5 & 16 & 49.9446 & 30.4829 & 49.6751 & 30.4081 & $269.516+74.816 j$ \\
\hline 17 & 16 & 17 & 45.0751 & 27.5581 & 44.8718 & 27.5016 & $203.282+56.43 j$ \\
\hline 18 & 17 & 18 & 40.2718 & 24.6516 & 40.0649 & 24.6046 & $206.862+47.064 j$ \\
\hline 19 & 18 & 19 & 35.4649 & 21.7546 & 35.3177 & 21.7211 & $147.26+33.504 j$ \\
\hline 20 & 19 & 20 & 30.7177 & 18.8711 & 30.6063 & 18.8457 & $111.33+25.328 j$ \\
\hline 21 & 20 & 21 & 26.0063 & 15.9957 & 25.8950 & 15.9766 & $111.358+19.126 j$ \\
\hline 22 & 21 & 22 & 21.2950 & 13.1266 & 21.2197 & 13.1137 & $75.272+12.928 j$ \\
\hline 23 & 22 & 23 & 16.6197 & 10.2637 & 16.5643 & 10.2542 & $55.388+9.514 j$ \\
\hline 24 & 23 & 24 & 11.9643 & 7.4042 & 11.9451 & 7.4009 & $19.26+3.308 j$ \\
\hline 25 & 24 & 25 & 7.3451 & 4.5509 & 7.3405 & 4.5501 & $4.552+0.782 j$ \\
\hline 26 & 25 & 26 & 2.7405 & 1.7001 & 2.7400 & 1.7000 & $0.508+0.088 j$ \\
\hline 27 & 6 & 27 & 4.5031 & 2.8805 & 4.5011 & 2.8802 & $1.986+0.342 j$ \\
\hline 28 & 27 & 28 & 3.0011 & 1.9202 & 3.0002 & 1.9200 & $0.884+0.152 j$ \\
\hline 29 & 28 & 29 & 1.5002 & 0.9600 & 1.5000 & 0.9600 & $0.22+0.038 j$ \\
\hline 30 & 9 & 30 & 4.5641 & 2.7607 & 4.5621 & 2.7604 & $2.002+0.344 j$ \\
\hline 31 & 30 & 31 & 3.4221 & 2.0704 & 3.4206 & 2.0701 & $1.502+0.258 j$ \\
\hline 32 & 31 & 32 & 2.2806 & 1.3801 & 2.2801 & 1.3800 & $0.5+0.086 j$ \\
\hline 33 & 32 & 33 & 1.1401 & 0.6900 & 1.1400 & 0.6900 & $0.084+0.014 j$ \\
\hline
\end{tabular}

TABLE 5: Search results for position and capacity of load reduction in a 34-bus system.

\begin{tabular}{lccccccc}
\hline $\begin{array}{l}\text { Initial load reduction } \\
\text { position } \\
\text { (node) }\end{array}$ & $\begin{array}{c}\text { Initial load reduction } \\
\text { capacity } \\
\text { (MW) }\end{array}$ & $\begin{array}{c}\text { Final load reduction } \\
\text { position } \\
\text { (node) }\end{array}$ & \multicolumn{2}{c}{$\begin{array}{c}\text { Final load reduction } \\
\text { position } \\
(\mathrm{MW})\end{array}$} & $\begin{array}{c}\text { Total power loss } \\
\text { after load reduction } \\
\text { (MW) }\end{array}$ & $\begin{array}{c}\text { Time con- } \\
\text { sumption } \\
(\mathrm{s})\end{array}$ \\
\hline 7 & $b$ & $P_{a}$ & $P_{b}$ & $a$ & $b$ & $P_{a}$ & $P_{b}$ \\
\hline
\end{tabular}

describe the next step after figuring out the optimal load scheduling scheme as follows. The results of Table 5 are used as the reference values of the closed loop load control of ACs. The closed loop control strategy by adjusting the temperature set point offset of ACS proposed in [37] is used as the control method. The period of load control is selected from 12:00 p.m. to 16:00 p.m. Figure 6 illustrates the effect of the AC load control based on the PSO tuning parameters of the 


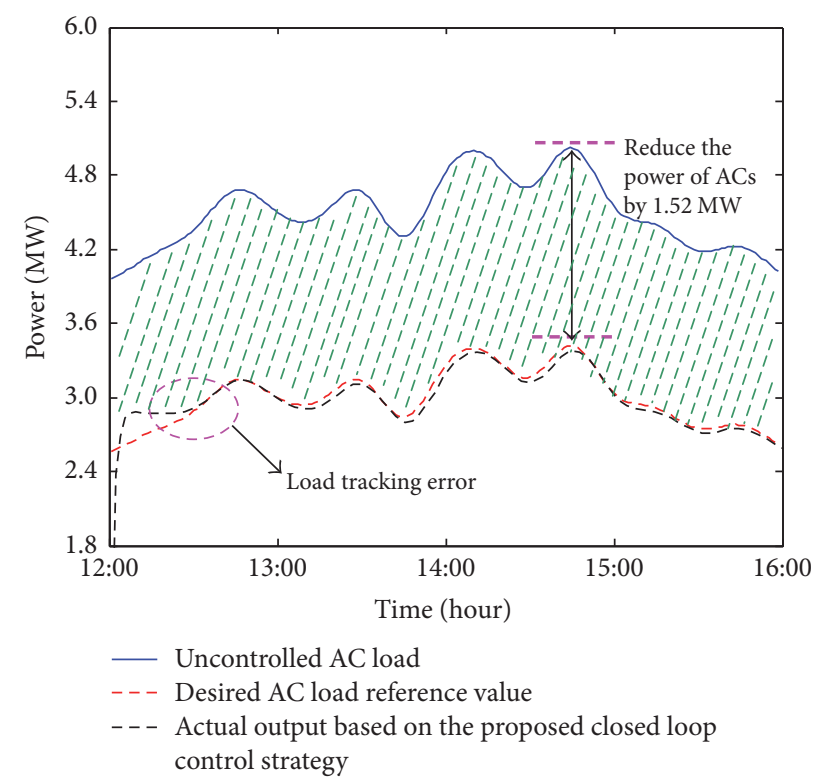

FIGURE 6: A comparison between the aggregated power of ACs without any control, the desired AC load reference value for load shifting, and the actual output power of AC load based on PSO tuning parameters of the PID controller.

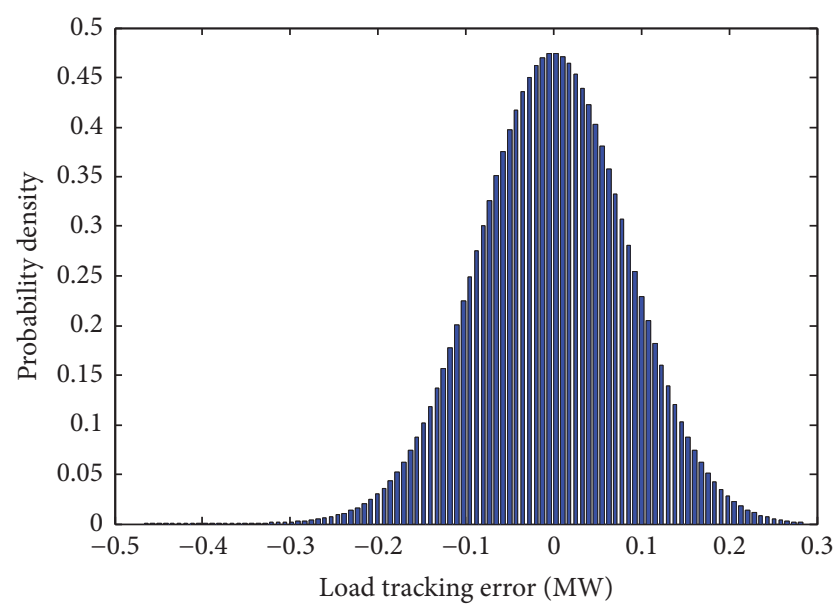

FIgURe 7: Probability density distribution of the tracking error between the actual output power and the reference value.

PID controller for load reduction on a hot day. The upper blue curve represents the power baseline of ACs without any control, the middle red dashed curve is the desired AC load reference value for load reduction, and the black dashed line at the bottom represents the actual output power of AC loads based on the proposed control algorithm. Throughout the control period, the output power of the ACs has been following the reference value closely, and the tracking error is small. Figure 7 shows the probability density distribution of the tracking error between the actual output and the reference value. As can be seen, the probability density is maximal when the load tracking error is $0 \mathrm{MW}$.
TABLE 6: Voltage amplitude and phase angle of each node after peak reduction.

\begin{tabular}{|c|c|c|}
\hline Node number & $\begin{array}{l}\text { Voltage amplitude } \\
\text { (p.u.) }\end{array}$ & $\begin{array}{c}\text { Voltage phase } \\
\text { angle } \\
\left({ }^{\circ}\right)\end{array}$ \\
\hline 0 & 1 & 0 \\
\hline 1 & 0.995 & 0.0505 \\
\hline 2 & 0.9907 & 0.0948 \\
\hline 3 & 0.9846 & 0.2044 \\
\hline 4 & 0.9794 & 0.2995 \\
\hline 5 & 0.9746 & 0.3898 \\
\hline 6 & 0.9713 & 0.4696 \\
\hline 7 & 0.9695 & 0.5119 \\
\hline 8 & 0.9671 & 0.5592 \\
\hline 9 & 0.9659 & 0.5845 \\
\hline 10 & 0.9654 & 0.5937 \\
\hline 11 & 0.9965 & 0.5955 \\
\hline 12 & 0.9904 & 0.1026 \\
\hline 13 & 0.9901 & 0.1098 \\
\hline 14 & 0.99 & 0.1117 \\
\hline 15 & 0.99 & 0.1118 \\
\hline 16 & 0.9706 & 0.465 \\
\hline 17 & 0.9673 & 0.5279 \\
\hline 18 & 0.9636 & 0.6104 \\
\hline 19 & 0.9608 & 0.6773 \\
\hline 20 & 0.9583 & 0.7356 \\
\hline 21 & 0.9554 & 0.8147 \\
\hline 22 & 0.9532 & 0.88 \\
\hline 23 & 0.9511 & 0.9416 \\
\hline 24 & 0.9499 & 0.9714 \\
\hline 25 & 0.9494 & 0.9829 \\
\hline 26 & 0.9493 & 0.9863 \\
\hline 27 & 0.9709 & 0.478 \\
\hline 28 & 0.9707 & 0.4836 \\
\hline 29 & 0.9706 & 0.4864 \\
\hline 30 & 0.9656 & 0.5924 \\
\hline 31 & 0.9652 & 0.6003 \\
\hline 32 & 0.965 & 0.6043 \\
\hline 33 & 0.965 & 0.6056 \\
\hline
\end{tabular}

Table 6 shows the voltage amplitude and phase angle of each node with the optimal peak reduction scheme. Figure 8 shows a comparison of the node voltage amplitude and phase angle before and after reducing AC loads for the 34-bus system. It can be seen that, after the load reduction, the voltage amplitude of each node has increased, still within 10\% of the voltage constraints. The voltage deviation is lower than that before the peak reduction and the voltage phase angle difference is reduced. Table 7 shows the transmission power 
TABLE 7: The transmission power and line loss of each branch after load reduction.

\begin{tabular}{|c|c|c|c|c|c|c|c|}
\hline \multirow[b]{2}{*}{ Line number } & \multirow[b]{2}{*}{ Node $i$} & \multirow[b]{2}{*}{ Node $j$} & \multicolumn{2}{|c|}{ Start node } & \multicolumn{2}{|c|}{ End node } & \multirow[b]{2}{*}{$\begin{array}{l}\text { Power loss of each line } \\
\text { (kVA) }\end{array}$} \\
\hline & & & $\begin{array}{c}P \\
(\mathrm{MW})\end{array}$ & $\begin{array}{c}Q \\
\text { (MVar) }\end{array}$ & $\begin{array}{c}P \\
(\mathrm{MW})\end{array}$ & $\begin{array}{c}Q \\
\text { (MVar) }\end{array}$ & \\
\hline 1 & 0 & 1 & 94.5062 & 56.8913 & 93.9179 & 56.6500 & $588.2896+241.3496 j$ \\
\hline 2 & 1 & 2 & 89.3179 & 53.8000 & 88.8305 & 53.6000 & $487.3701+199.9467 j$ \\
\hline 3 & 2 & 3 & 84.2372 & 50.7495 & 83.5657 & 50.5631 & $671.4577+186.3913 j$ \\
\hline 4 & 3 & 4 & 78.9657 & 47.7131 & 78.4211 & 47.5619 & $544.6558+151.1921 j$ \\
\hline 5 & 4 & 5 & 73.8211 & 44.7119 & 73.3388 & 44.5780 & $482.2849+133.8784 j$ \\
\hline 6 & 5 & 6 & 23.3966 & 14.0957 & 23.2939 & 14.0780 & $102.7347+17.6453 j$ \\
\hline 7 & 6 & 7 & 18.7908 & 11.1975 & 18.7465 & 11.1899 & $44.2374+7.598 j$ \\
\hline 8 & 7 & 8 & 14.1465 & 8.3399 & 14.1090 & 8.3335 & $37.5431+6.4482 j$ \\
\hline 9 & 8 & 9 & 11.0290 & 6.6235 & 11.0136 & 6.6208 & $15.4277+2.6498 j$ \\
\hline 10 & 9 & 10 & 6.4495 & 3.8601 & 6.4462 & 3.8595 & $3.2989+0.5666 j$ \\
\hline 11 & 10 & 11 & 1.8462 & 1.0095 & 1.8460 & 1.0095 & $0.207+0.0356 j$ \\
\hline 12 & 2 & 12 & 4.5933 & 2.8506 & 4.5914 & 2.8502 & $1.9395+0.3331 j$ \\
\hline 13 & 12 & 13 & 3.1514 & 1.9502 & 3.1502 & 1.9500 & $1.2162+0.2089 j$ \\
\hline 14 & 13 & 14 & 1.7102 & 1.0500 & 1.7100 & 1.0500 & $0.1784+0.0306 j$ \\
\hline 15 & 14 & 15 & 0.2700 & 0.1500 & 0.2700 & 0.1500 & $0.0021+0.0004 j$ \\
\hline 16 & 5 & 16 & 49.9422 & 30.4823 & 49.6732 & 30.4077 & $268.9821+74.6673 j$ \\
\hline 17 & 16 & 17 & 45.0732 & 27.5577 & 44.8703 & 27.5013 & $202.8779+56.3173 j$ \\
\hline 18 & 17 & 18 & 40.2703 & 24.6513 & 40.0639 & 24.6044 & $206.4491+46.9699 j$ \\
\hline 19 & 18 & 19 & 35.4639 & 21.7544 & 35.3169 & 21.7209 & $146.9649+33.4365 j$ \\
\hline 20 & 19 & 20 & 30.7169 & 18.8709 & 30.6058 & 18.8457 & $111.1067+25.2782 j$ \\
\hline 21 & 20 & 21 & 26.0058 & 15.9957 & 25.8947 & 15.9766 & $111.1351+19.0881 j$ \\
\hline 22 & 21 & 22 & 21.2947 & 13.1266 & 21.2195 & 13.1137 & $75.12+12.9023 j$ \\
\hline 23 & 22 & 23 & 16.6195 & 10.2637 & 16.5643 & 10.2542 & $55.2758+9.4939 j$ \\
\hline 24 & 23 & 24 & 11.9643 & 7.4042 & 11.9450 & 7.4009 & $19.2218+3.3015 j$ \\
\hline 25 & 24 & 25 & 7.3450 & 4.5509 & 7.3405 & 4.5501 & $4.5425+0.7802 j$ \\
\hline 26 & 25 & 26 & 2.7405 & 1.7001 & 2.7400 & 1.7000 & $0.5067+0.087 j$ \\
\hline 27 & 6 & 27 & 4.5031 & 2.8805 & 4.5011 & 2.8802 & $1.9814+0.3403 j$ \\
\hline 28 & 27 & 28 & 3.0011 & 1.9202 & 3.0002 & 1.9200 & $0.8808+0.1513 j$ \\
\hline 29 & 28 & 29 & 1.5002 & 0.9600 & 1.5000 & 0.9600 & $0.2202+0.0378 j$ \\
\hline 30 & 9 & 30 & 4.5641 & 2.7607 & 4.5621 & 2.7604 & $1.9936+0.3424 j$ \\
\hline 31 & 30 & 31 & 3.4221 & 2.0704 & 3.4206 & 2.0701 & $1.4956+0.2569 j$ \\
\hline 32 & 31 & 32 & 2.2806 & 1.3801 & 2.2801 & 1.3800 & $0.4986+0.0856 j$ \\
\hline 33 & 32 & 33 & 1.1401 & 0.6900 & 1.1400 & 0.6900 & $0.0831+0.0143 j$ \\
\hline
\end{tabular}

and line loss of each branch after load reduction. Figure 9 shows a comparison of the active power at each receiving node before and after reducing AC loads for the 34-node system. It can be seen that after peak reduction at node 7 and load 23, the active and reactive power of each branch have decreased.

Figure 10 shows a comparison of the power transmitted over lines 4-5 and the system power loss and the line loss rate of the distribution network before and after reducing $\mathrm{AC}$ loads. As can be seen from the left plot in Figure 10, the power transmitted over lines 4-5 dropped from 90.4014 MVA to 85.8421 MVA, which indicates that transmission congestion in lines can be eliminated by the flexible load scheduling based on the proposed search algorithm. The right plot in Figure 10 shows that, after the smart load reduction, the total power loss of the distribution network dropped from 4.4345 MW to $3.7902 \mathrm{MW}$, and the line loss rate was reduced from $4.5639 \%$ to $3.0935 \%$. In addition, the total active and reactive power of the system were changed to $94.5062 \mathrm{MW}$ and 56.8913 MVar, respectively. Compared with that before 
TABLE 8: Comparisons of different parameters of power distribution network before and after AC loads reduction.

\begin{tabular}{lccccc}
\hline Performance index & $\begin{array}{c}\text { System power loss of } \\
\text { the distribution } \\
\text { network } \\
(\mathrm{MW})\end{array}$ & $\begin{array}{c}\text { Line loss rate } \\
(\%)\end{array}$ & $\begin{array}{c}\text { Voltage amplitude at } \\
\text { the end of the line } \\
(\mathrm{kV})\end{array}$ & $\begin{array}{c}\text { Power transmitted } \\
\text { over lines 4-5 } \\
(\mathrm{MVA})\end{array}$ & $\begin{array}{c}\text { Voltage offset rate of } \\
\text { the terminal node } \\
(\%)\end{array}$ \\
\hline Before load reduction & 4.4345 & 4.5639 & 10.0790 & 90.4014 & 4.0095 \\
After load reduction & 3.7902 & 3.0935 & 10.1325 & 85.8421 \\
\hline
\end{tabular}

Voltage profile before and after reducing air conditioning load
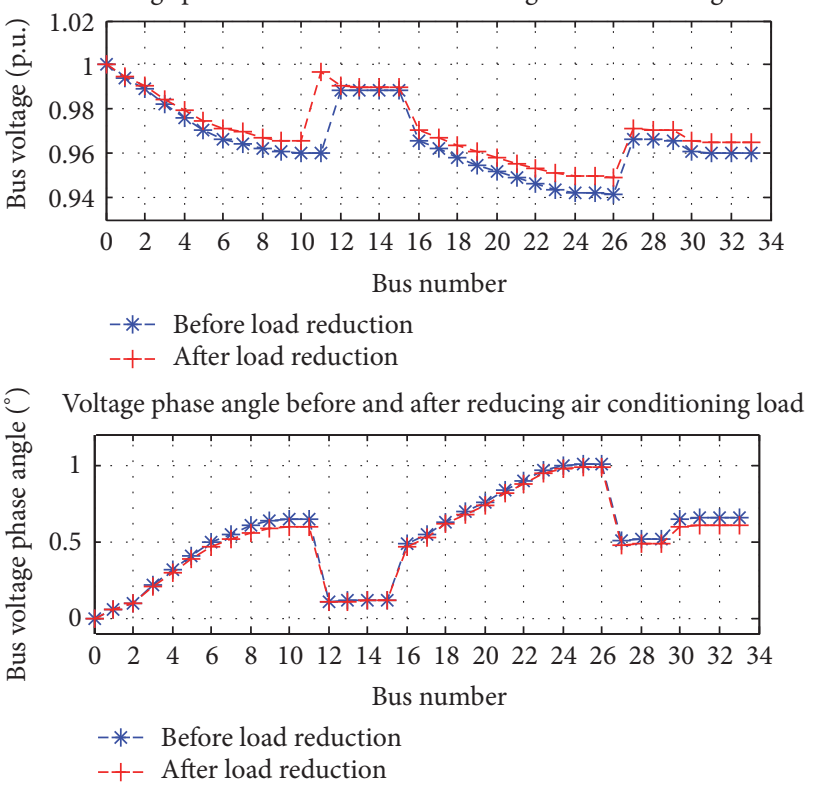

Figure 8: A comparison of the node voltage amplitude and phase angle before and after reducing air conditioning loads for the 34-bus system.

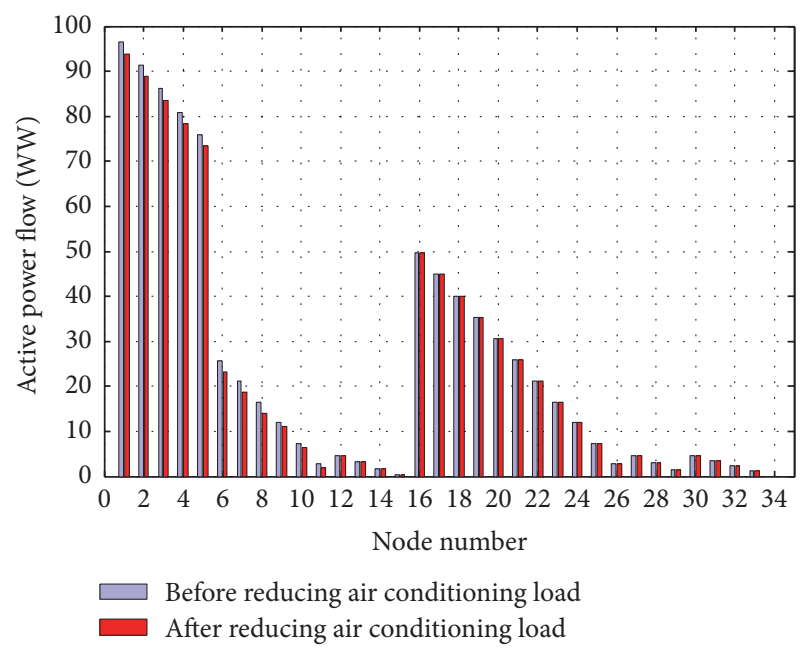

FIGURE 9: A comparison of the receiving active power of each node before and after reducing AC loads for the 34-node system.

load scheduling, the total power loss of the distribution network is reduced by $14.5293 \%$, and the voltage amplitude at the end of the line rises to $10.1325 \mathrm{kV}$. In addition, the voltage offset rate at the end node is reduced from $4.0095 \%$ to $3.5 \%$. Table 8 shows comparisons of different parameters of power distribution network before and after AC loads reduction.

\section{Conclusions}

In this paper, a model of AC loads scheduling in urban distribution network is built. The improved tabu search algorithm repeatedly calls the power flow calculation and neighborhood search to find the optimal position for load reduction and to figure out the appropriate reduction capacity at each node exactly. In the case study, comparisons of different parameters of power distribution network before and after AC loads scheduling are performed to verify the proposed method.

The main contribution of this paper can be summarized as follows. By appropriately reducing AC loads, distribution network reconfiguration and load shedding can be replaced. The proposed method can not only ensure users' comfort but also avoid cumbersome switching operations and the loss of power. The back/forward sweep algorithm is used to calculate the power flow. In order to meet the requirement of DLC strategy of distribution network, an improved tabu search technique is proposed to minimize the resistive line losses and to eliminate the transmission congestion in lines under normal operating conditions. In the proposed algorithm, the process of the neighborhood search is divided into two parts: location search to find the exact position of the nodes chosen to carry out load reduction in the distribution network, and capacity search to determine the accurate capacity of load reduction. It is proved that the algorithm can find the optimal solution quickly.

\section{Conflicts of Interest}

The authors declare no conflicts of interest.

\section{Authors' Contributions}

Beibei Wang and Xiaoqing Hu designed the model, performed the simulations, and revised the paper. Peifeng Shen and Wenlu Ji proposed the research topic and analyzed the data. Yang Cao analyzed the data. Jiaping Tang polished the manuscript and corrected spelling and grammar mistakes. All authors contributed to the writing of the manuscript and have read and approved the final manuscript. 

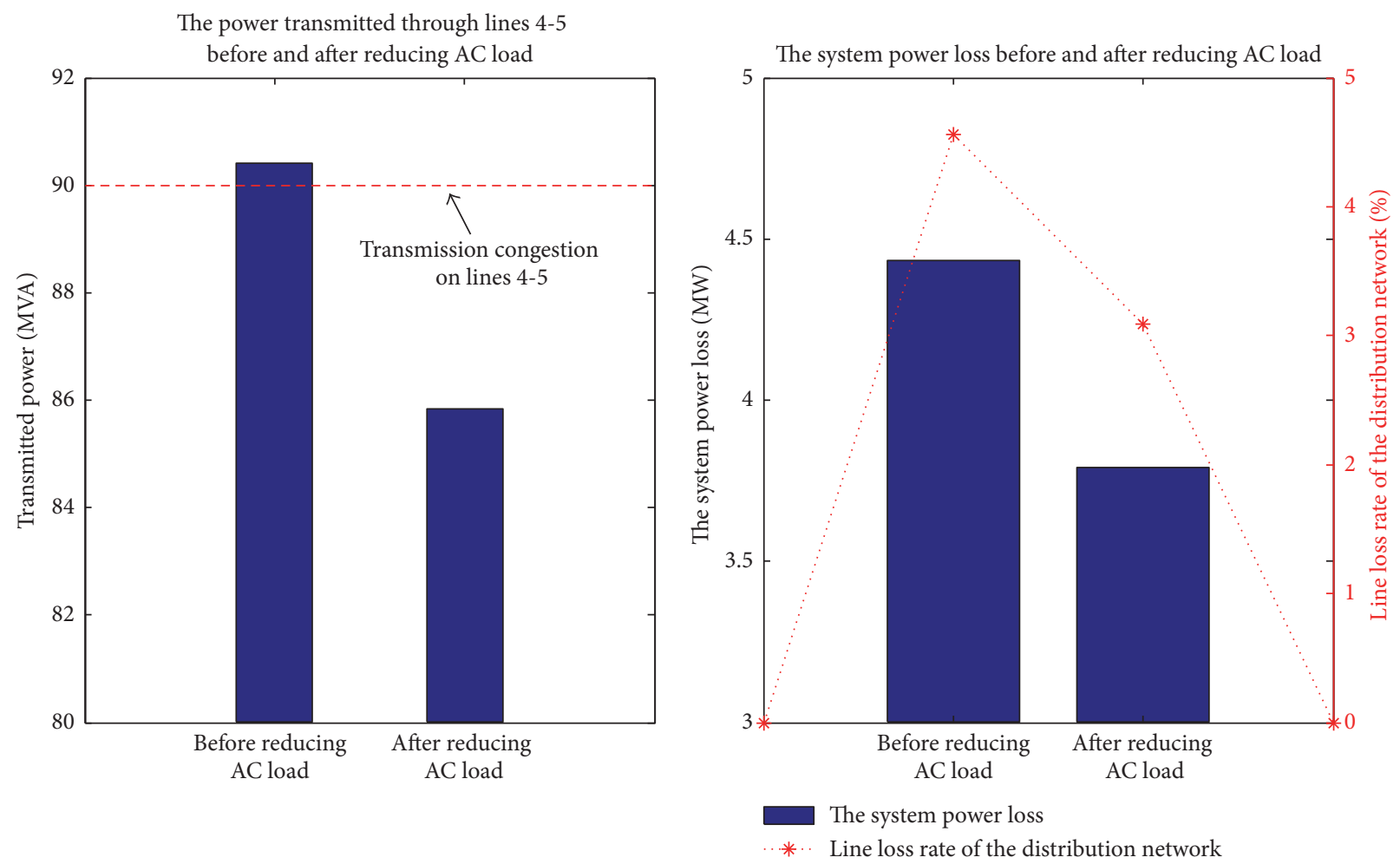

FIGURE 10: The power transmitted over lines 4-5 and the system power loss and the line loss rate of the distribution network before and after reducing AC loads.

\section{Acknowledgments}

This work was supported by the National Natural Science Foundation of China $(71471036,51277028)$ and the S\&T Foundation of State Grid Corporation of China (Key Technologies of District Power Grid Dispatch Considering Flexible Demand Side Resources).

\section{References}

[1] I. Roytelman, B. K. Wee, and R. L. Lugtu, "Volt/var control algorithm for modern distribution management system," IEEE Transactions on Power Systems, vol. 10, no. 3, pp. 1454-1460, 1995.

[2] X. W. Wang, J. Gao, X. X. Wei, and Y. X. Hou, "A novel fault line selection method based on improved oscillator system of power distribution network," Mathematical Problems in Engineering, vol. 2014, Article ID 901810, 19 pages, 2014.

[3] D. Dohnal, On-load tap changer, vol. 9, U.S. Patent, 522. 2015-69.

[4] D. Das, "Reactive power compensation for radial distribution networks using genetic algorithm," International Journal of Electrical Power and Energy Systems, vol. 24, no. 7, pp. 573-581, 2002.

[5] S. Hirodontis, H. Li, and P. A. Crossley, "Load shedding in a distribution network," in Proceedings of the 1st International Conference on Sustainable Power Generation and Supply, (SUPERGEN '09), Nanjing, China, April 2009.

[6] R. A. Gupta and M. Y. Chow, "Networked control system: overview and research trends," IEEE Transactions on Industrial Electronics, vol. 57, no. 7, pp. 2527-2535, 2010.
[7] J. Marmolejo A, R. Rodríguez, O. Cruz-Mejia, and etal., "Design of a distribution network using primal-dual decomposition," Mathematical Problems in Engineering, vol. 2016, 2016.

[8] S. Civanlar, J. J. Grainger, H. Yin, and S. S. H. Lee, "Distribution feeder reconfiguration for loss reduction," IEEE Transactions on Power Delivery, vol. 3, no. 3, pp. 1217-1223, 1988.

[9] M. E. Baran and F. F. Wu, "Network reconfiguration in distribution systems for loss reduction and load balancing," IEEE Transactions on Power Delivery, vol. 4, no. 2, pp. 1401-1407, 1989.

[10] K. Nara, A. Shiose, M. Kitagawa, and T. Ishihara, "Implementation of genetic algorithm for distribution systems loss minimum re-configuration," IEEE Transactions on Power Systems, vol. 7, no. 3, pp. 1044-1051, 1992.

[11] S. K. Goswami and S. K. Basu, "A new algorithm for the reconfiguration of distribution feeders for loss minimization," IEEE Transactions on Power Delivery, vol. 7, no. 3, pp. 1484-1491, 1992.

[12] T. P. Wagner, A. Y. Chikhani, and R. Hackam, "Feeder reconfiguration for loss reduction: an application of distribution automation," IEEE Transactions on Power Delivery, vol. 6, no. 4, pp. 1922-1933, 1991.

[13] H. D. Chiang and R. Jean-Jumeau, "Optimal network reconfigurations in distribution systems. II. Solution algorithms and numerical results," IEEE Transactions on Power Delivery, vol. 5, no. 3, pp. 1568-1574, 1990.

[14] W. P. Luan, M. R. Irving, and J. S. Daniel, "Genetic algorithm for supply restoration and optimal load shedding in power system distribution networks," IEE Proceedings: Generation, Transmission and Distribution, vol. 149, no. 2, pp. 145-151, 2002.

[15] Y. Xu, W. Liu, and J. Gong, "Stable multi-agent-based load shedding algorithm for power systems," IEEE Transactions on Power Systems, vol. 26, no. 4, pp. 2006-2014, 2011. 
[16] A. Praktiknjo, "The value of lost load for sectoral load shedding measures: The German case with 51 sectors," Energies, vol. 9, no. 2, pp. 1-17, 2016.

[17] E. Carrano, R. T. N. Cardoso, R. H. C. Takahashi, and et al., "Power distribution network expansion scheduling using dynamic programming genetic algorithm," IET Generation, Transmission \& Distribution, vol. 2, no. 3, pp. 444-455, 2008.

[18] A. Borghetti, M. Bosetti, S. Grillo et al., "Short-term scheduling and control of active distribution systems with high penetration of renewable resources," IEEE Systems Journal, vol. 4, no. 3, pp. 313-322, 2010.

[19] K. Maki, S. Repo, and P. Jarventausta, Effect of wind power based distributed generation on protection of distribution network.

[20] S. Wang, X. Jiang, and C. Wang, "Power flow analysis of distribution network containing wind power generators," Power System Technology, vol. 21, 2006.

[21] A. Yazdani and P. P. Dash, "A control methodology and characterization of dynamics for a photovoltaic (PV) system interfaced with a distribution network," IEEE Transactions on Power Delivery, vol. 24, no. 3, pp. 1538-1551, 2009.

[22] V. F. Martins and C. L. T. Borges, "Active distribution network integrated planning incorporating distributed generation and load response uncertainties," IEEE Transactions on Power Systems, vol. 26, no. 4, pp. 2164-2172, 2011.

[23] P. H. Nguyen, W. L. Kling, G. Georgiadis, M. Papatriantafilou, L. A. Tuan, and L. Bertling, "Distributed routing algorithms to manage power flow in agent-based active distribution network," in Proceedings of the IEEE PES Innovative Smart Grid Technologies Conference Europe, ISGT Europe 2010, swe, October 2010.

[24] J. Driesen and F. Katiraei, "Design for distributed energy resources," IEEE Power and Energy Magazine, vol. 6, no. 3, pp. 30-39, 2008.

[25] D. Pudjianto, C. Ramsay, and G. Strbac, "Virtual power plant and system integration of distributed energy resources," IET Renewable Power Generation, vol. 1, no. 1, pp. 10-16, 2007.

[26] H. Wang, K. Meng, F. Luo, Z. Y. Dong, Z. Xu, and K. P. Wong, "A hierarchical optimization framework for aggregating thermostatically controlled loads to minimize real-time thermal rating of overhead distribution lines," in Proceedings of the 2014 6th China International Conference on Electricity Distribution, (CICED '14), pp. 1769-1773, Shenzhen, China, September 2014.

[27] G. Strbac, "Demand side management: benefits and challenges," Energy Policy, vol. 36, no. 12, pp. 4419-4426, 2008.

[28] J. Lai, H. Zhou, W. Hu, D. Zhou, and L. Zhong, "Smart Demand Response Based on Smart Homes," Mathematical Problems in Engineering, vol. 2015, Article ID 912535, 2015.

[29] C.-M. Chu and T.-L. Jong, "A novel direct air-conditioning load control method," IEEE Transactions on Power Systems, vol. 23, no. 3, pp. 1356-1363, 2008.

[30] D. S. Callaway and I. A. Hiskens, "Achieving controllability of electric loads," Proceedings of the IEEE, vol. 99, no. 1, pp. 184199, 2011.

[31] S. H. Lee and C. L. Wilkins, "A practical approach to appliance load control analysis: a water heater case study," IEEE Transactions on Power Apparatus and Systems, vol. 102, no. 4, pp. 10071013, 1983.

[32] R. Bhatnagar and S. Rahman, "Direct load control: relationships between electric utility experiences/assessments and system characteristics," IEEE Transactions on Power Apparatus and Systems, vol. 8, no. 8, pp. 2168-2175, 1985.
[33] Y.-Y. Hsu and C.-C. Su, "Dispatch of direct load control using dynamic programming," IEEE Transactions on Power Systems, vol. 6, no. 3, pp. 1056-1061, 1991.

[34] D.-C. Wei and N. Chen, "Air conditioner direct load control by multi-pass dynamic programming," IEEE Transactions on Power Systems, vol. 10, no. 1, pp. 307-313, 1995.

[35] J. Chen, F. N. Lee, A. M. Breipohl, and R. Adapa, "Scheduling direct load control to minimize system operational cost," IEEE Transactions on Power Systems, vol. 10, no. 4, pp. 1994-2001, 1995.

[36] A. Molina, A. Gabaldon, J. Fuentes, and F. Canovas, "Approach to multivariable predictive control applications in residential HVAC direct load control," in Proceedings of the 2000 Power Engineering Society Summer Meeting, pp. 1811-1816, Seattle, WA, USA.

[37] X. Hu, B. Wang, S. Yang, T. Short, and L. Zhou, "A closedloop control strategy for air conditioning loads to participate in demand response," Energies, vol. 8, no. 8, pp. 8650-8681, 2015. 


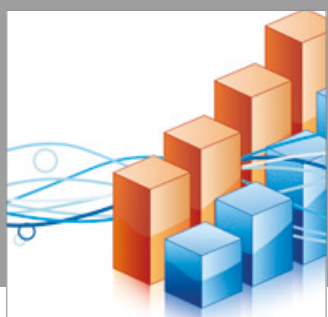

Advances in

Operations Research

vatersals

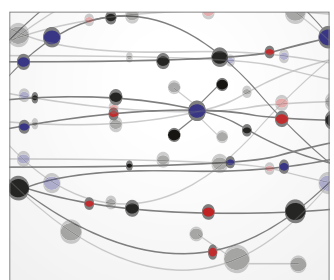

\section{The Scientific} World Journal
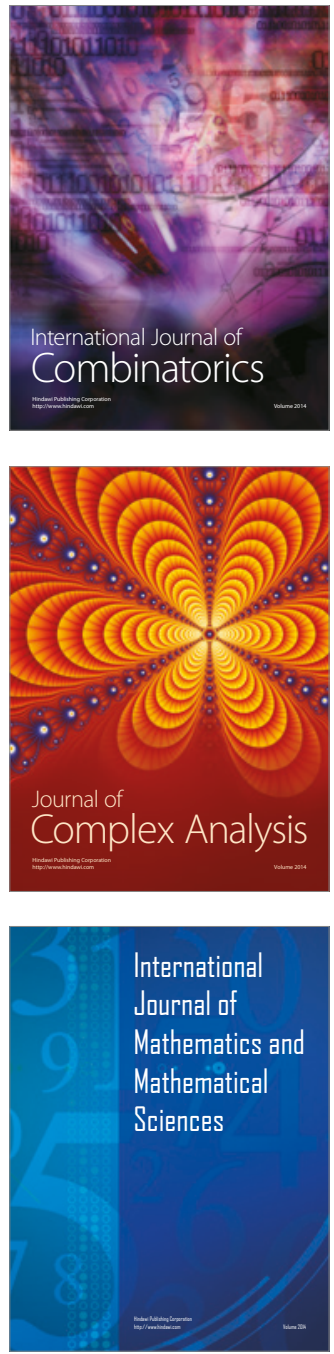
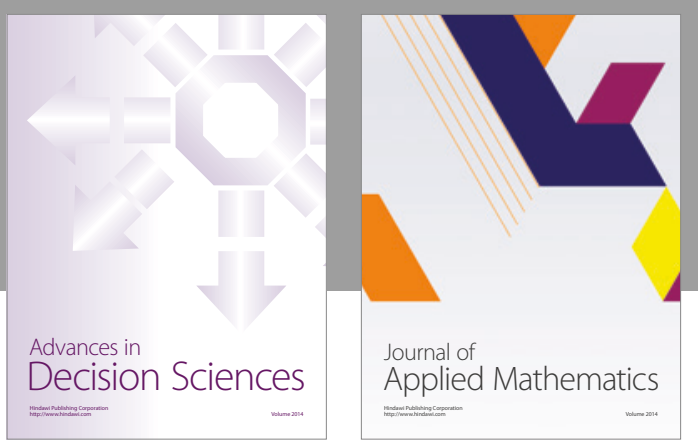

Algebra

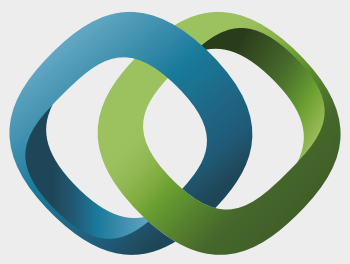

\section{Hindawi}

Submit your manuscripts at

https://www.hindawi.com
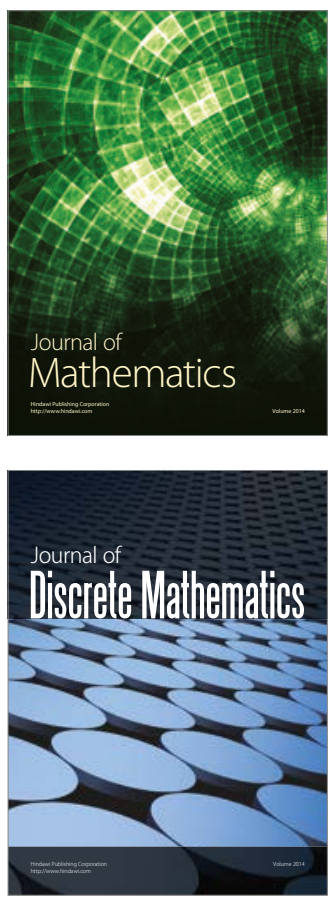

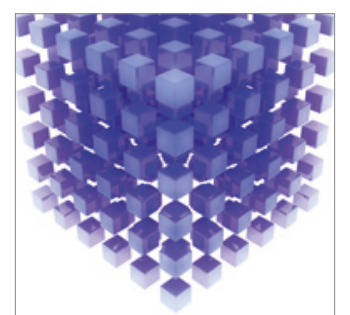

Mathematical Problems in Engineering
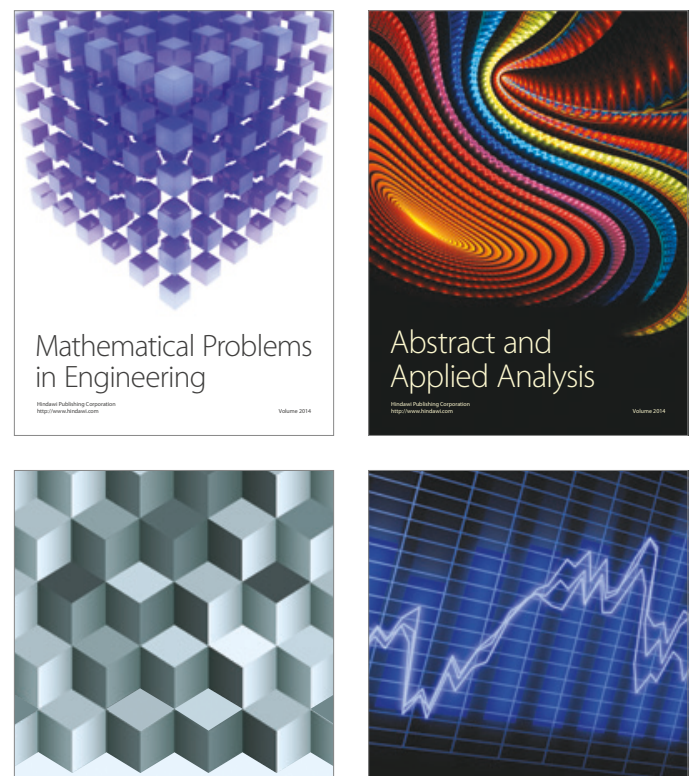

Journal of

Function Spaces

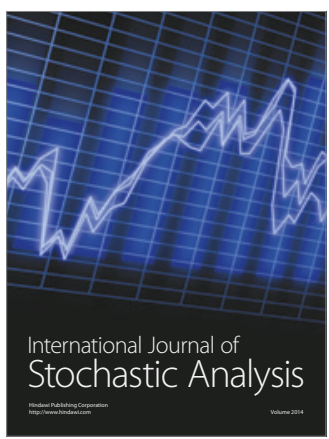

Probability and Statistics
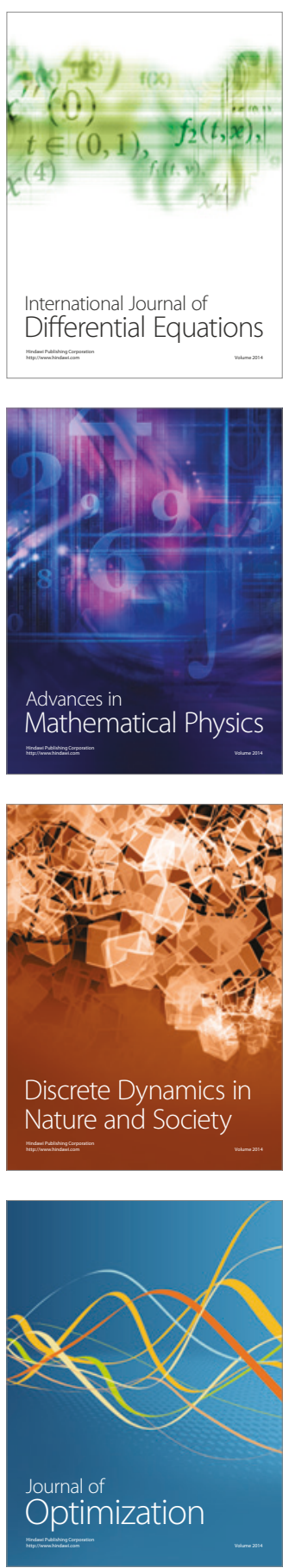